\title{
Short Term Duty Electrical Machines
}

Puvan Arumugam and Chris Gerada

\begin{abstract}
${ }^{\Phi}$ Abstract -- This paper presents a design of a short term duty electrical machine working in an extreme environment consisting of $8^{\circ} \mathrm{C}$ ambient temperature and altitudes of over $30,000 \mathrm{~m}$. Higher power density is a key factor in the design wherein the machine's operation is required only for a short duty. The requirement of high power-to-weight and power-tovolume leads to a Permanent Magnet (PM) machine design, which is then optimized. Different slot and pole combinations, with both concentrated and distributed winding arrangements are considered. For the optimization, a Genetic Algorithm (GA) is used where analytical electromagnetic and thermal models are adopted together with Finite Element (FE) methods. It is shown that the adopted thermal model provides sufficient accuracy when predicting temperature rise within the winding. It is also shown that the designs are thermally limited where the pole numbers are limited by volt-amps drawn from the converter. The design consisting of a high slot number allows for improving the heat dissipation from the machine and thus, the weight can be minimized for the given torque production.
\end{abstract}

Index Terms--Analytical, design, extreme environment, electromagnetic, optimization, permanent magnet, short-term, thermal management

\section{INTRODUCTION}

$T$ HE operation of electrical machines under extreme environments is becoming essential and technologies to cope with such conditions are undergoing significant development. One of the extreme conditions is a high temperature environment where the performance and lifetime of the electrical machines are restricted due to both winding insulation properties and magnetic materials. This can be overcome through managing temperature within the machine which allows the machine to perform and survive. Alternatively, materials that can endure the harsh operating conditions can be used but the overall performance will be compromised due to thermal effects and the poorer electrical or magnetic properties of the materials. Nevertheless, the performance can be improved if the trade-offs between the electromagnetic, thermal and structural properties and associated material properties are considered in the early stage of the design.

In this paper, a high power-density electrical machine, operating at both a high ambient temperature and altitude without any external cooling, is developed considering electromagnetic, thermal and structural interactions. The operation of the machine is limited to a few seconds as it will

Puvan Arumugam is with Force Engineering, Shepshed, LE12 9NH, UK (email: puvan@force.co.uk)

Chris Gerada is with the Power Electronics Machines and Control group, faculty of Engineering, University of Nottingham, Nottingham, NG7 2RD, UK (e-mail: chris.gerada@nottingham.ac.uk) be used as an emergency recovery unit. It must provide a large power-to-weight ratio within a very narrow envelope, high torque, and high acceleration. From the trade-off study, a Permanent Magnet (PM) machine offers the best design. Different slot and pole combinations with both concentrated and distributed winding arrangements are considered. For the optimization, a Genetic Algorithm (GA) is used, where a combined analytical electromagnetic and thermal models are adopted together with Finite Element (FE) methods. It is shown that the adopted thermal model predicts the temperature rise within the winding effectively. It is also shown that the design of the PM machine is thermally limited wherein the pole numbers are limited by the volt-amps drawn from converter. Heat dissipation can be improved and thus, high power density can be achieved, if a high slot number is selected for the design.

\section{DESIGN REQUIREMENTS}

Since the application considered here is related to aerospace, the weight and the volume are the key constraints. The thermal limits of the design are dictated by the lack of available cooling and the short operation of the system. The design must also meet following constraints.

1) the design envelope is limited to $200 \mathrm{~mm} \times 200 \mathrm{~mm} \times$ $200 \mathrm{~mm}$ (length $\mathrm{x}$ width $\mathrm{x}$ depth);

2) the power density should be higher than $16 \mathrm{~kW} / \mathrm{kg}$;

3) the design should provide maximum starting torque and high efficiency;

4) the maximum converter DC link voltage should be less than $700 \mathrm{~V}$

5) the ambient temperature is over $80^{\circ} \mathrm{C}$.

Since the power-density is a key design target, the design has to be traded between power-to-volume and power-toweight. The machine must also be able to accelerate to speed within 1 second as the operational time is limited to 12 seconds. The machine is therefore ultimately designed to fulfil the performance to minimize the overall size and weight together with reduced rotor mass.

From initial trade-off study between different candidates, it has been found that a PM solution which is thermally limited provides high power density $[1,2]$ compared to both an Induction Machine (IM) and a Switch Reluctance Machine (SRM). It is also seen that an IM is severely limited by magnetic saturation and thus, to achieve the required performance the machine would have to be oversized or loaded with high current [3]. This results in poor efficiency. The SRM is the heaviest option due to the requirement of high peak torque. It is worth noting that the SRM has a significant torque ripple which also makes this topology unsuitable for the application considered [4]. The PM is therefore selected for further optimization. The detailed 
design optimization of the PM machine is presented in the next section.

\section{DESIGN OPTIMIZATION}

The key design optimization target is to produce a PM machine which has a reduced volume and mass for a given power output. Fig.1 represents the process involved in the optimization of the design. The optimization process starts with a Surface mounted PM machine with selected Slot $(S)$ and Pole $(P)$ combinations and associated winding arrangements. Both Concentrated Winding $(\mathrm{CW})$ and Distributed Winding (DW) arrangements are considered for different slot and pole selections in which the number of slots is limited to 30 and 60 respectively. This is mainly because of the manufacturing difficulties involved when a high slot number is selected for a limited envelope but also because a high pole number introduces high switching losses in the converter.

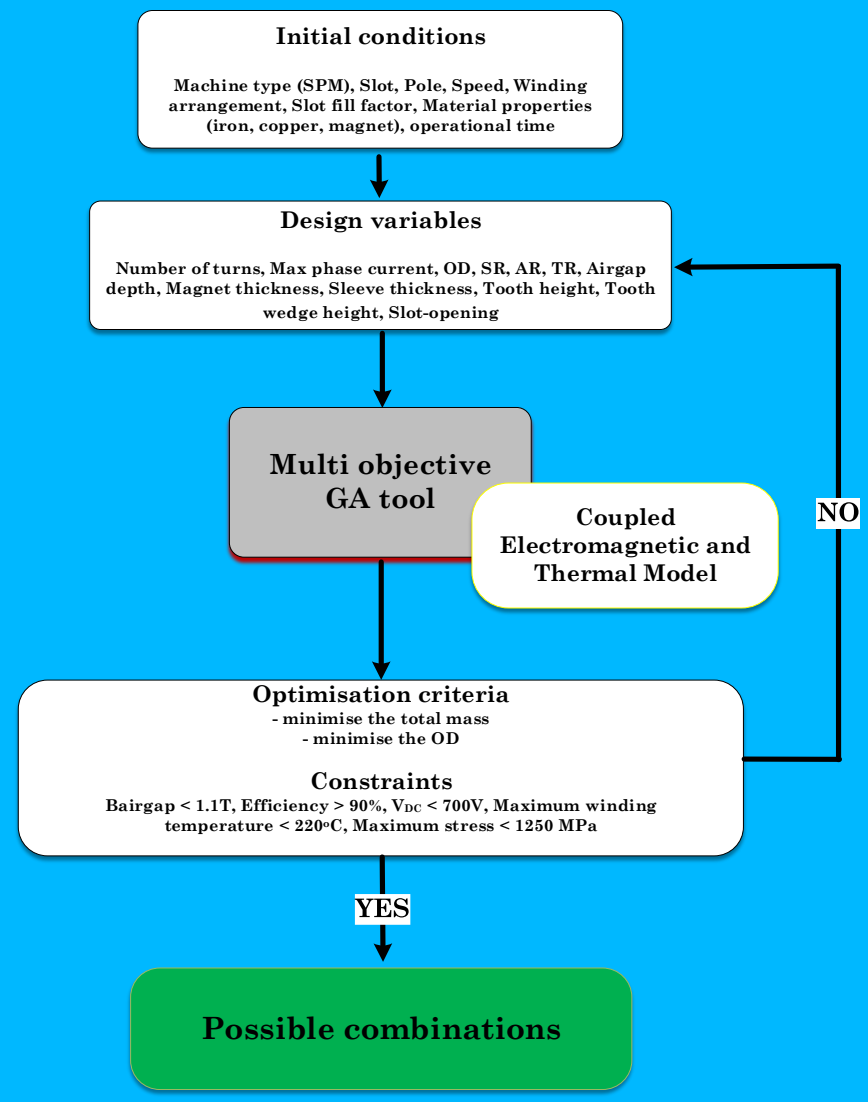

Fig.1. Illustration of the design process

Outer diameter $(O D)$, split ratio $(S R)$, aspect ratio $(A R)$, tooth width to slot ratio $(T R)$, airgap depth $\left(l_{g}\right)$, slot-opening $\left(S_{o}\right)$, tooth-tip height $\left(h_{t}\right)$, magnet span $\left(\alpha_{m}\right)$, magnet height $\left(h_{m}\right)$, sleeve thickness, number of turns per slot $\left(N_{t}\right)$ and phase current $\left(I_{p}\right)$ are set (within a range) as design parameters and limited by following constraints.

1) no-load air gap flux density $\leq 1.1 \mathrm{~T}$;

2) efficiency $\geq 90 \%$;

3) converter voltage limit $\leq 700 \mathrm{~V}$;

4) maximum stress acting on the sleeve $\leq 1250 \mathrm{MPa}$;
5) maximum hot spot winding temperature $\left(T_{\max }\right) \leq$ insulation breakdown temperature of $220^{\circ} \mathrm{C}$.

A multi objective genetic algorithm (GA) is adopted for the optimization process in which a $1 \mathrm{D}$ electromagnetic and thermal model are used during the design process. Once the design routine is completed, a design that has lower weight and volume is selected from the possible solutions and then Finite element (FE) is adopted for design verification and refinement.

The method used for optimization is a Non-dominated Sorting Genetic Algorithm (NSGAII) which was developed in [5]. As in other evolutionary algorithms, first the NSGA-II algorithm generates a random initial population which evolves during the optimization process towards the global optimum. The objective functions are evaluated for each individual and then ranked. The offspring population is generated from the current population by selection, crossover and mutation. Finally, the process is repeated until the algorithm stops or a stopping condition (in this case a maximum number of iterations) is satisfied. The functionality of the optimization tool can be found in detail in [5].

As explained previously, to compute the electromagnetic, thermal and structural performances a combined analytical model is developed and the model integrated within the GA optimization tool. The analytical model includes the following assumptions:

1) the laminated magnetic material has an infinite permeability;

2) the slotting effects are neglected;

3) only the fundamental winding factor harmonic is considered;

4) iron losses due to localized saturations are neglected;

5) slot fill factor of 0.5 is assumed;

6) high frequency effect on winding is not taken into account;

7) magnet demagnetization and localized stress are neglected;

8) the thermal hot-spot occurs at the winding and there is no heat dissipation from the windings to the surrounding material.

Though abovementioned phenomena are not considered within the design optimization routine, these are systematically taken into account in the optimized final design via FE.

\section{A. Electromagnetic model}

The analytical modelling of electric machines relies on the electromagnetic field and a generalized theorem. The electromagnetic torque/ force associated with the machine can be estimated either from the system energy/co-energy variation or radial and tangential airgap flux density, with incremental rotor displacement. The energy/co-energy and airgap flux density are functions of the current and parameters such as resistances and inductances associated with the electrical machines. Thus, the precision of the analytical model that estimates the electromagnetic torque in rotating machines depends on the accuracy of the machines' parameters. 
The fundamental relationship for torque production in PM machines is linked to Lorentz force in which the force $F$ on a single conductor carrying a current $I$ in a uniform magnetic field $B$ can be expressed as

$$
F=B I L
$$

If an electrical machine is considered to have $N_{p h}$ conductors per phase carrying a current $I$ and the windings are represented in an equivalent current sheet around the airgap perimeter, the linear current density $A$ for a unit length can be described as

$$
A=\frac{3 N_{p h} I}{\pi d_{b}}
$$

where $d_{b}$ is stator bore diameter and factor 3 represents the number of phase windings. Hence, the force on the conductors can be expressed as a shear/normal stress $\sigma$,

$$
\sigma=\frac{F}{\text { Area }}=B A
$$

where the flux density $B$ is known as the magnetic loading and the linear current density $A$ is also known as the electric loading. Since the machine has rotor diameter $d_{r}$ and stack length of $l_{s t k}$, the sheer stress $\sigma$ which produces a torque $T$ can be written as:

$$
T=F \frac{d_{r}}{2}=\sigma A r e a \frac{d_{r}}{2}=\frac{\sigma \pi d_{r}^{2} l_{s t k}}{2}=2 V_{r} \sigma
$$

where $V_{r}$ is the rotor volume of the considered machine. Thus, equation (4) can be re-written as (5).

$$
T=2 V_{r} B A
$$

From (4) and (5), it is evident that the torque generated by the machine is proportional to the product of its rotor volume $\left(\propto d^{2} l_{s t k}\right)$ and shear stress, where the shear stress is the product of the magnetic and electric loading.

In the design, the electrical loading is restricted by factors such as the allowable slot area to accommodate the winding, the achievable packing factor of copper $\left(K_{f}\right)$ in the stator slots, and the allowable copper current density based on the maximum allowable winding temperature rise. The magnetic loading is limited by saturation of the stator material used. Although the magnetic saturation is not considered in the model, it can be systematically included by knowing the properties of the stator material. Since the airgap flux density is known, the width of the stator tooth, and back iron thickness can be estimated by taking into account the saturation flux density at both stator tooth and back-iron. In parallel, the influence of the magnetic loading on current loading due to changes in the available slot area can also be calculated within the model.

The height of the magnet $\left(h_{m}\right)$ changes the flux density at the airgap, the induced electromotive force (emf) in the windings, and consequently the fundamental phase voltage.
Assuming that the maximum flux density in the airgap is limited by the saturation limit of stator iron, the height of the magnet can be estimated as follows

$$
h_{m}=\frac{\mu_{r} B_{g} l_{g}}{\left(B_{r}-B_{g}\right)}
$$

where $l_{g}$ is airgap length and, $\mu_{r}$ and $B_{r}$ are recoil permeability and remanence flux of the PM material respectively. $B_{g}$ is magnitude of the fundamental airgap flux density due to the PM and thus, based on magnetization distribution it can be represented as a function of airgap flux density by

$$
B_{g}=\frac{\pi B_{p}}{4 \sin \left(\frac{\pi \alpha}{2}\right)}
$$

where $\alpha$ is pole span of the PM.

To estimate the fundamental harmonic of the phase voltage, the back-emf $(e)$ and voltage drop across active (resistance - $R$ ) and passive components (inductance - $L$ and drop across iron - $V_{i}$ ) has to be calculated. These can be calculated from the following equations.

$$
\begin{gathered}
e=\frac{2 \pi f k_{w} N_{p h} B d_{r} l_{s t k}}{(p / 2)} \\
R=\frac{\rho\left(l_{s t k}+l_{e}\right)}{A_{s}} \\
L=P_{t} N_{p h}^{2}
\end{gathered}
$$

where $f$ is electrical frequency, $k_{w}$ is the winding factor associated to the considered winding arrangement, $l_{e}$ is the end winding length and $\rho$ is resistivity of the conductive medium in the slot. $P_{t}$ is the total permeance associated with both the geometry and the winding arrangement. The iron losses are estimated based on Bertotti's equation by averaging the flux density over a given area. From these parameters, the resultant phase voltage is computed.

Since the geometrical parameters associated with the design are known, the volume and the mass can be estimated based on the mass density of the material adopted.

\section{B. Structural model}

A method which estimates the stresses due to the centrifugal forces that act on the retaining Carbon Fiber (CF) sleeve is adopted [6]. In the model, a ring equivalent to the mass of both CF sleeves and the magnet is represented and the stress acting on the sleeve based on the total mass is estimated. Applied pre-stress for $\mathrm{CF}$ retention is not conceded within the model. A detailed model can be found in [6]. 


\section{Thermal model}

As previously mentioned, the thermal hot-spot is expected to occur at the winding due to high torque density requirements for a given operational time. To assess this temperature rise within the winding a thermal model is therefore adopted. This makes a basic assumption that during the operation all the losses generated by the windings go towards increasing the windings temperature and it has linear characteristics within the considered time interval. It is thus assumed that there is no heat transfer from the windings to the surrounding magnetic material. This represents the worstcase thermal condition within the slot. Hence, based on the winding losses, the temperature rise within the slot domain can be expressed as follows:

$$
T=\int_{t_{0}}^{t_{1}} \frac{I_{p}^{2} R_{\text {new }}}{m c_{p}} d t
$$

where,

$$
R_{\text {new }}=R_{i}\left(1+\alpha_{1}\left(T-T_{i}\right)\right)
$$

where $I_{p}$ is the phase current, $R_{i}$ is the initial resistance at the operating speed of the machine; $T_{i}$ is the initial temperature of the machine which is assumed equal to the ambient temperature $\left(80^{\circ} \mathrm{C}\right) ; m$ is the mass of the winding; $\alpha_{1}$ is the temperature coefficient of resistivity and $c_{p}$ is the specific thermal heat capacity of copper. Given that the machine is only under operation for a period of $t_{p}$, the final temperature of the machine $\left(T_{f}\right)$ can be re-written as

$$
T_{f}=\left[80+\left(\frac{I_{p}{ }^{2}\left(R_{i}+R_{i} \alpha_{1}\left(T-T_{i}\right)\right)}{m c_{p}} \cdot t_{p}\right)\right]{ }^{o} \mathrm{C}
$$

\section{RESULTS AND DISCUSSION}

Table I and Table II show the obtained design solutions for the considered slot and pole selections with CW and DW arrangements, respectively. From the results, it can be seen that amongst the designs, the 6-slot/4-pole is the heaviest solution. This is due to the low pole numbers and the low winding factor compared to other solutions. It can also be seen that the design cases are mostly limited by temperature; while a few cases, variants A11, A12, A13, B5 and B12, are electromagnetically restricted. Variants A11 to A13 consist of high pole numbers which limits the number of turns. As a result it reduces the current loading as the maximum current is limited. So to achieve the torque required, the design needs to be oversized which ultimately adds the weight to the design. This is clearly evident in the solutions obtained for A11, A12, A13 and B5.

Though the higher pole number is expected to provide a higher torque, the design variant A6 (which has higher pole number than A5 for same slot number) provides a heavier solution. This is mainly due to a smaller slot per pole number compared to A5; consequently it saturates the machine heavily than solution A5. This can further be seen from following groups which are concentrically wound.

- 9 slots with pole numbers 6 and 8 ;
- 12 slots with pole numbers 8,10 and 14 ;

- 18 slots with pole numbers 12 and 16 .

TABLE I

PERFORMANCE COMPARISON BETWEEN CONCENTRATED WOUND FRACTIONAL SLOT PM MACHINE TOPOLOGIES

\begin{tabular}{c|c|c|r|c|c|c|c}
\multicolumn{7}{|c}{ FRACTIONAL SLOT PM MACHINE TOPOLOGIES } \\
\hline \hline Variant & $S$ & $P$ & $q$ & $N p h$ & $T_{\max }$ & $\begin{array}{c}\text { Efficiency } \\
(\%)\end{array}$ & $\begin{array}{c}\text { Weight } \\
(\mathrm{pu})\end{array}$ \\
\hline $\mathrm{A} 1$ & 6 & 4 & 0.5 & 16 & 192 & 94.8 & 2.38 \\
\hline $\mathrm{A} 2$ & 9 & 6 & 0.5 & 15 & 184 & 94.3 & 1.52 \\
\hline $\mathrm{A} 3$ & 12 & 8 & 0.5 & 20 & 192 & 94.9 & 1.63 \\
\hline $\mathrm{A} 4$ & 9 & 8 & 0.375 & 15 & 195 & 94.8 & 1.59 \\
\hline $\mathrm{A} 5$ & 12 & 10 & 0.4 & 16 & 196 & 95.5 & 1.63 \\
\hline $\mathrm{A} 6$ & 12 & 14 & 0.285 & 16 & 156 & 94.7 & 1.72 \\
\hline $\mathrm{A} 7$ & 18 & 12 & 0.5 & 24 & 203 & 93.6 & 1.07 \\
\hline A8 & 18 & 16 & 0.375 & 18 & 183 & 94.7 & 1.13 \\
\hline $\mathrm{A} 9$ & 24 & 16 & 0.5 & 24 & 207 & 92.5 & 1.02 \\
\hline $\mathrm{A} 10$ & 27 & 18 & 0.5 & 27 & 203 & 94.0 & 1.03 \\
\hline $\mathrm{A} 11$ & 24 & 20 & 0.4 & $\mathbf{2 4}$ & 153 & 94.9 & 1.13 \\
\hline A12 & 24 & 22 & 0.363 & $\mathbf{1 6}$ & 138 & 95.8 & 1.56 \\
\hline A13 & 36 & 30 & 0.4 & $\mathbf{1 8}$ & 110 & 95.9 & 1.61 \\
\hline \hline
\end{tabular}

TABLE II

PERFORMANCE COMPARISON BETWEEN DISTRIBUTED WINDING PM MACHINE TOPOLOGIES

\begin{tabular}{c|c|r|r|r|r|c|c}
\hline \hline Variant & $S$ & $P$ & $q$ & $N p h$ & $T_{\max }$ & $\begin{array}{c}\text { Efficiency } \\
(\%)\end{array}$ & $\begin{array}{c}\text { Weight } \\
(p u)\end{array}$ \\
\hline B1 & 6 & 4 & 0.5 & 16 & 185 & 93.9 & 2.23 \\
\hline B2 & 12 & 4 & 1 & 24 & 201 & 92.5 & 1.40 \\
\hline B3 & 18 & 4 & 1.5 & 24 & 210 & 92.5 & 1.39 \\
\hline B4 & 18 & 6 & 1 & 24 & 188 & 94.4 & 1.29 \\
\hline B5 & 27 & 6 & 1.5 & $\mathbf{1 8}$ & 197 & 94.0 & 1.34 \\
\hline B6 & 24 & 4 & 2 & 24 & 204 & 91.7 & 1.30 \\
\hline B7 & 24 & 8 & 1 & 24 & 200 & 94.8 & 1.29 \\
\hline B8 & 36 & 6 & 2 & 24 & 202 & 93.2 & 1.16 \\
\hline B9 & 36 & 8 & 1.5 & 24 & 202 & 93.7 & 1.09 \\
\hline B10 & 36 & 12 & 1 & 24 & 196 & 94.9 & 1.08 \\
\hline B11 & 48 & 8 & 2 & 24 & 206 & 93.7 & 1.06 \\
\hline B12 & 60 & 10 & 2 & $\mathbf{2 0}$ & 183 & 94.7 & 1.00 \\
\hline \hline
\end{tabular}

In contrast, the distributed wound solution becomes lighter when the slot per pole number is smaller, for example:

- 18 slots with pole numbers 4 and 6 ;

- 24 slots with pole numbers 4 and 8 ;

- 36 slots with pole numbers 6,8 and 12 .

This is mainly because of the back-iron depth which becomes smaller with an increasing pole number. As a result, the volume and mass of the back-iron reduces. A similar observation can be made from the following slot per pole per phase groups.

- $q=1: 12$ slot $/ 4$ pole, 18 slot $/ 6$ pole, 24 slot $/ 8$ pole and 36 slot/12 pole;

- $q=1.5: 18$ slot/4 pole, 24 slot/6 pole and 36 slot $/ 8$ pole;

- $q=2: 24$ slot $/ 4$ pole, 36 slot $/ 6$ pole, 48 slot 8 pole and 60 slot/6 pole.

\section{A. Observation of slot, pole number and winding type}

Fig.2 shows the weight trend of the optimized machines which includes different winding arrangements. From the results, it can clearly be seen that the weight of the machine which has distributed winding arrangements reduces with an increase in both slot and pole numbers. This clearly explains that the solution which has high slot and pole number provides the required performance with minimal mass. But, it is worth noting that increasing the slot number further will introduce manufacturing challenges and cost. 


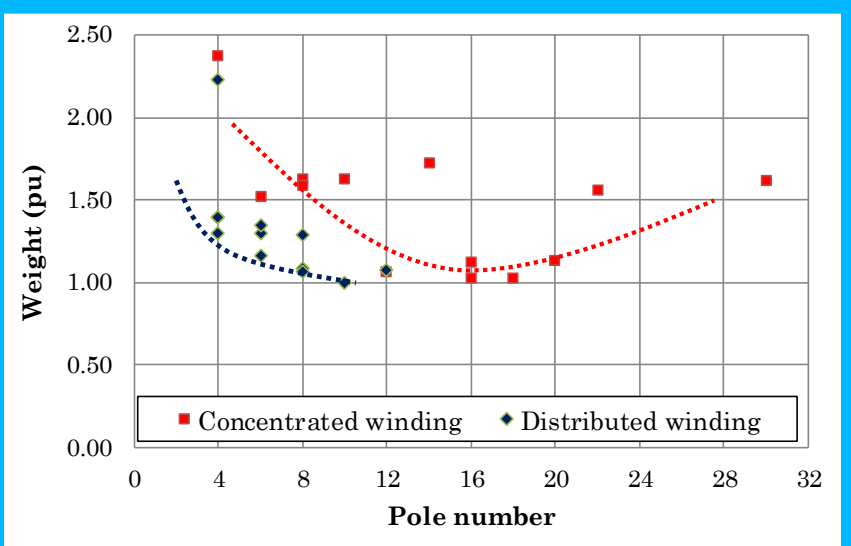

(a)

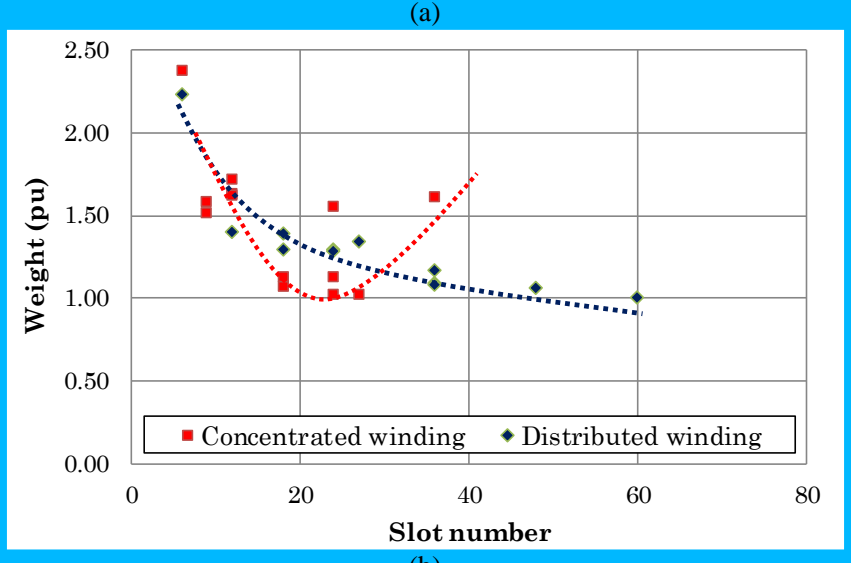

(b)

Fig.2. Weight comparison between different (a) pole numbers and (b) slot numbers

Although similar characteristics can be seen in the concentrated winding machine solution, it can be seen to have an optimum slot and pole combination. Increasing the number of slots and poles would not be effective due to electromagnetic constraints such as number of turns and the voltage limit from the converter.

\section{B. Thermal aspects}

Another major design constraint is thermal limitation. Throughout the design process it has been considered to be an enclosed machine without a casing and using natural cooling. The adopted model is expected to provide a good level of accuracy since the machine is only operated at the linear region of temperature rise.

Fig. 3 shows the analytically obtained hot spot temperature in the winding compared to the results computed through the MotorCad thermal model [7]. Both methods show strong agreement within the given operational interval. These results clarify that the heat generated due to the winding losses is entirely accommodated within the slot for the considered operational time. The adopted model is therefore valid and applicable for the thermal prediction where the machine is under operation for a few seconds.

From the results, it is also worth highlighting that the higher slot number has very good thermal characteristics, with the hotspot temperature settling more quickly than the designs consisting of lower slot numbers. This is mainly due to the losses being distributed throughout the slot and the very good thermal path between slot and the back-iron. This is not the case for lower slot numbers in which the slot area is larger resulting in poorer heat removal.

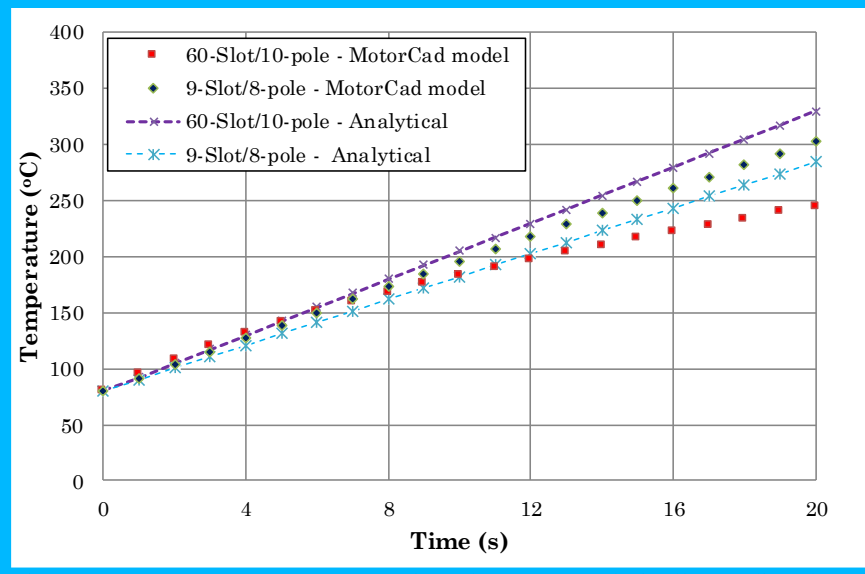

Fig.3. Hotspot temperature comparison between analytically predicted and MotorCad model

Temperature rises for a given time for optimized machines are shown in Fig.4. From the results, it is clear that the majority of the design cases are limited by the winding temperature, but variants A11 to A13 show low temperature rises. As previously mentioned, these designs are electromagnetically limited and have low winding losses compared to other cases. It also can be seen that larger slot numbers have lower temperature gradients. This further confirms that increasing the slot numbers allows for the accommodation of higher winding losses.

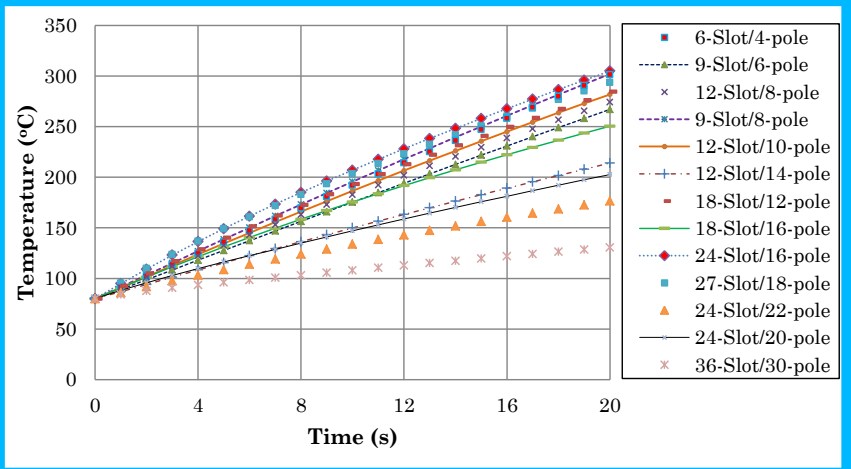

(a)

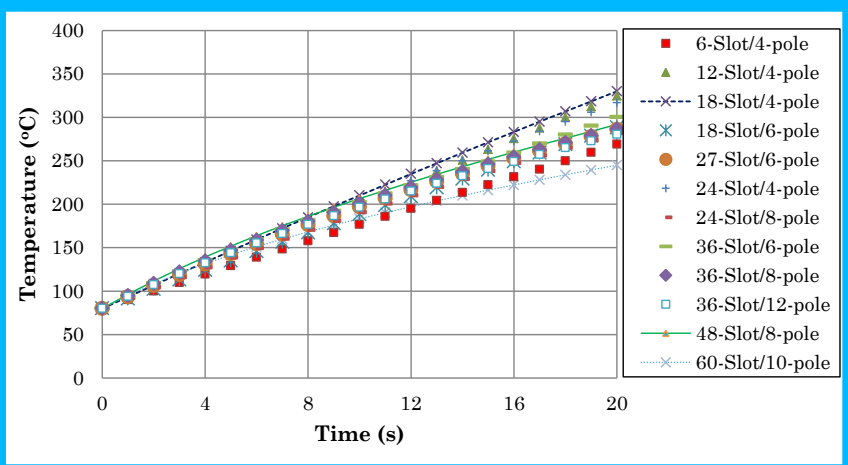

(b)

Fig.4. Temperature rise within the winding (hot spot) for different slot and pole variants with (a) $\mathrm{CW}$ arrangement and (b) DW arrangement 
Given the performance requirement of high power-density, the initial design analysis indicates that both the 60 -slot/10pole design and 24-slot/16-pole design can be selected for the application. Though both designs are feasible, these have pros and cons. The 60 -slot/10-pole design has slightly less mass than the 24-slot/16-pole design, which can be further reduced if the end windings are wound effectively. Due to the distributed winding arrangement, the rotor has lower losses than the concentrated winding solution employed in $24 / 16$ machine. In addition, the 60/10 design uses less PMs than the 24/16 machine, but the initial stator manufacturing will be costly and challenging due to requirement of 60 slots. By contrast, the 24/16 machine design downsizes the cost and challenge, and improves the slot fill due to the windings which are wound only around a single tooth. This reduces the DC losses compared to the $60 / 10$ solution. The key disadvantage of employing the $24 / 16$ design is the operational frequency which is higher than the 60/10 machine solution. This may increase the switching losses associated with the converter counterpart, but on the other hand, it may reduce the harmonic losses associated with the machine.

\section{CONCLUSION}

In this paper, a design and analysis of a short-term electrical machine targeted for an aerospace application has been presented. A PM machine was selected and designed adopting integrated electromagnetic and thermal models within a GA optimization tool. FE methods were used for design refinement, including non-linearity, which wasn't considered in the analytical model. The design which fulfilled the application criteria with the minimum weight was selected from optimized designs, which consist of different slot, pole and winding arrangements. It was shown that the adopted thermal model provides an accurate prediction of the temperature rise within the winding. It was also shown that the designs are thermally limited where the pole numbers are limited by volt-amps drawn from the converter. Higher slot numbers also improves the heat dissipation from the machine and thus, the weight can be minimized for the given torque production.

\section{REFERENCES}

[1] M. v. d. Geest, H. Polinder, J. A. Ferreira, and M. Christmann, "Power Density Limits and Design Trends of High-Speed Permanent Magnet
Synchronous Machines," IEEE Transactions on Transportation Electrification, vol. 1, pp. 266-276, 2015.

[2] A. M. E.-. Refaie, J. P. Alexander, S. Galioto, P. B. Reddy, K. K. Huh, P. d. Bock, et al., "Advanced High-Power-Density Interior Permanent Magnet Motor for Traction Applications," IEEE Transactions on Industry Applications, vol. 50, pp. 3235-3248, 2014.

[3] E. B. Agamloh, A. Cavagnino, and S. Vaschetto, "Impact of Number of Poles on the Steady-State Performance of Induction Motors," IEEE Transactions on Industry Applications, vol. 52, pp. 1422-1430, 2016.

[4] M. R. Feyzi, S. R. M. Aghdam, and Y. Ebrahimi, "A comprehensive review on the performance improvement in switched reluctance motor design," in Electrical and Computer Engineering (CCECE), 2011 24th Canadian Conference on, 2011, pp. 000348-000353.

[5] K. Deb, A. Pratap, S. Agarwal, and T. Meyarivan, "A fast and elitist multiobjective genetic algorithm: NSGA-II," IEEE Transactions on Evolutionary Computation, vol. 6, pp. 182-197, 2002.

[6] A. Binder, T. Schneider, and M. Klohr, "Fixation of buried and surface mounted magnets in high-speed permanent magnet synchronous motors," in Industry Applications Conference, 2005. Fourtieth IAS Annual Meeting. Conference Record of the 2005, 2005, pp. 2843-2848 Vol. 4.

[7] Motor Design Limited, "About Motor Cad", [On Line]. Available: http://www.motor-design.com/motorcad.php [Accessed: October 2015].

\section{BIOGRAPHIES}

Puvan Arumugam (M'11) received the B.Eng. (Hons.) degree in electrical and electronic engineering from The University of Nottingham, Nottingham, U.K., in 2009, and the Ph.D. degree in electrical machines and drives from The University of Nottingham, Nottingham, U.K., in 2013. He subsequently worked as a researcher within the Power Electronics, Machines, and Control Group, The University of Nottingham, working on electric aircraft propulsion. He is currently a Senior Project Engineer with the Force Engineering Ltd, Shepshed, UK.

His current research interests include electrical machines and drives, electromechanical devices and systems, and analytical computation of electromagnetic fields. Dr. Arumugam was awarded a Hermes Fellowship supported by Technology Transfer Office, The University of Nottingham in 2014 .

Chris Gerada (M'05) received the Ph.D. degree in numerical modeling of electrical machines from The University of Nottingham, Nottingham, U.K., in 2005. He was subsequently a researcher with The University of Nottingham, where he was involved in high-performance electrical drives and the design and modeling of electromagnetic actuators for aerospace applications. Since 2006, he has been the Project Manager of the GE Aviation Strategic Partnership. In 2008, he was appointed as a Lecturer in electrical machines, an Associate Professor in 2011, and a Professor with The University of Nottingham, in 2013.

His current research interests include the design and modeling of highperformance electric drives and machines. He serves as an Associate Editor of the IEEE Transactions On Industry Applications and is the Chair of the IEEE Industrial Electronics Society Electrical Machines Committee. 